\title{
Re-infection with Fasciola gigantica 6-months post-treatment with triclabendazole in cattle from mobile pastoralist husbandry systems at Lake Chad
}

Helena Greter ${ }^{a, b}$, Annour A. Batil ${ }^{c}$, Idriss O. Alfaroukh ${ }^{c}$, Felix Grimm $^{d}$, Bongo N. Ngandoloc, Jennifer Keiser $^{\mathrm{a}, \mathrm{b}}$, Jürg Utzinger ${ }^{\mathrm{a}, \mathrm{b}}$, Jakob Zinsstag ${ }^{\mathrm{a}, \mathrm{b}}$, Jan Hattendorf ${ }^{\mathrm{a}, \mathrm{b}, *}$

${ }^{a}$ Swiss Tropical and Public Health Institute, Basel, Switzerland

${ }^{\mathrm{b}}$ University of Basel, Basel, Switzerland

' Institut de Recherche en Elevage pour le Développement, N'Djamena, Chad

d Institute for Parasitology, Vetsuisse Faculty, University of Zurich, Zurich, Switzerland

* Corresponding author. E-mail address: jan.hattendorf@unibas.ch (J. Hattendorf) 


\section{A B S T R A C T}

At Lake Chad in central Africa, livestock fascioliasis caused by Fasciola gigantica represents a major veterinary health problem, particularly in cattle reared in mobile pastoralist husbandry systems. We assessed the effect of a single dose of triclabendazole against fascioliasis in cattle in a mobile pastoralist setting towards the end of the dry season. Within the cattle herds of 14 groups of mobile pastoralists, 375 cattle were randomly selected. A faecal sample was obtained from each animal to determine the prevalence of $F$. gigantica. Animals were administered a single oral dose of triclabendazole $(12 \mathrm{mg} / \mathrm{kg})$. A second faecal sample was obtained 6-month post-treatment after cattle had returned from the annual migration cycle. Faecal samples were fixed in sodium acetate-acetic acid-formalin (SAF), and examined for F. gigantica using the sedimentation technique. From the 375 cattle enrolled at baseline, 198 animals (53\%) in 12 groups of mobile pastoralists were re-sampled at the 6month follow-up. Baseline prevalence did not differ noteworthy between animals lost to follow-up and those re-examined. At baseline, bovine fascioliasis prevalence in cattle with follow-up data was $41.9 \%$ (95\% confidence interval $(\mathrm{Cl}) 35.2-48.9 \%)$. At the 6-month posttreatment follow-up, the prevalence was $46.0 \%$ (95\% Cl 39.2-52.9\%), ranging between $0 \%$ and $75 \%$ at the herd level. The mean faecal egg counts at the unit of the herd were higher at follow-up compared to baseline. The observed persistent high prevalence of $F$. gigantica infection in cattle shows that a single pre-rainy season treatment does not prevent rapid reinfection despite the partial migration away from the high-risk areas at Lake Chad into drier areas. A locally adapted strategic control package for fascioliasis in cattle in the Lake Chad area ought to integrate targeted triclabendazole treatment and seasonal transhumance practices.

\section{Keywords:}

Fascioliasis

Fasciola gigantica

Cattle 
Mobile pastoralism

Triclabendazole

Chad 


\section{Introduction}

Livestock fascioliasis caused by Fasciola gigantica and F. hepatica is of considerable veterinary importance and economic relevance, explained by reduced productivity and fertility in cattle and productivity losses (Wamae et al., 1998; Kaplan, 2001). Alongside the negative health outcomes, treatment expenses and condemnation of infected livers at slaughter impact negatively on the livelihoods of people depending on livestock (Suleiman et al., 2015). Although precise estimates of national, regional and global losses have yet to be determined, the impact is assumed to be considerable (WHO, 2015).

In the Sahelian belt of Africa, livestock is traditionally managed in mobile pastoralist husbandry systems that provides a livelihood to an estimated 20 million people (De Haan et al., 2014). According to the Chadian "Plan National de Développement Sanitaire II (PNDS2) 2013-2015", livestock production contributes an estimated $24 \%$ to the gross domestic product (GDP), which represents the second most important contribution to the national income after the export of crude oil (40\% GDP). The Lake Chad area and its seasonal flood plains are home to mobile pastoralists with a seasonally high population density of indigenous livestock. Especially towards the end of the dry season, large numbers of cattle, goat and sheep are grazing on Lake Chad shores (Jean-Richard et al., 2015). The basin is long-known to be a trematode-endemic area, including Paramphistomum spp., Schistosoma bovis and F. gigantica (Bouchet et al., 1969; Quéval et al., 1971; Tager-Kagan, 1978). A recent abattoir study in the south-eastern Lake Chad area revealed that close to $70 \%$ of indigenous cattle were infected with Fasciola spp. with a slight trend to lower infection rates from August to October, including the rainy season (Jean-Richard et al., 2014). A study among mobile pastoralists on knowledge, attitudes and practice on fascioliasis and the use of anthelminthic drugs in the region showed high awareness of the disease but irregular and non-strategic use of anthelminthic drugs because of limited access, availability and financial resources. Available drugs - albendazole and bithionol sulfoxide - were administered only to those animals showing severe illness (Greter et al., 2016). 
In Africa and elsewhere, strategic anthelminthic treatments of livestock have been demonstrated to be effective and beneficial (Zinsstag et al., 2000; Akkari et al., 2011). However, there is a gap in knowledge on strategic anthelminthic treatment experience in mobile pastoralist husbandry systems, specifically from the Sahel. To our knowledge, strategic control of fascioliasis in cattle in Chad has yet to be considered.

Triclabendazole is marketed for veterinary use since 1983 (Keiser et al., 2005). It is the drug of choice for the treatment of fascioliasis caused by $F$. hepatica and F. gigantica. In controlled studies in cattle, efficacy has been shown to be as high as $96.5 \%$ and $97.8 \%$ (Rapic et al., 1988; Richards et al., 1990). An efficacy of 90\% (Lecuyer et al., 1985) and $100 \%$ has been reported from naturally infected cattle (Craig and Huey, 1984; Lecuyer et al., 1985; Stansfield et al., 1987). Triclabendazole is also the treatment of choice for treating human fascioliasis (WHO, 2007). In contrast to older flukicides whose activity is limited to adult liver flukes, triclabendazole is effective against all live stages of Fasciola flukes in the final host (Keiser et al., 2005). Currently, triclabendazole is not commercially available in Chad and in none of the neighbouring countries (Keiser et al., 2005; Keyyu et al., 2009; Greter et al., 2016). To our knowledge, triclabendazole treatment against fascioliasis in naturally infected cattle in a mobile pastoralist setting has not been determined thus far.

Here, we present results of a single-arm intervention trial of triclabendazole treatment on bovine fascioliasis in naturally infected Chadian cattle in a mobile pastoralist husbandry system. The rationale for treating cattle at the end of the dry season was that cattle would be cleared from infection prior to migrating away from the wetlands of Lake Chad towards semiarid pasture East of Lake Chad with lowered risk of re-infection during the rainy season (Jean-Richard et al., 2014).

\section{Materials and methods}

\subsection{Study area and local husbandry practices}

This study was conducted in three regions: (i) Chari-Baguirmi; (ii) Hadjer-Lamis; and (iii) Lac on the eastern shores of Lake Chad in Chad. The regions are located in the Sahelian 
ecological zone with borders to Cameroon, Niger and Nigeria in the West. The area is inhabited by fishermen, a sedentary population that predominantly lives of agriculture, and different ethnic groups of mobile pastoralists with large numbers of livestock (Jean-Richard et al., 2015). Participating animals originated from herds owned by one of the four predominant ethnic groups of mobile pastoralists: (i) Arabs; (ii) Buduma; (iii) Fulani; and (iv) Gorane.

The climate consists of a rainy season from June to October, a cool and dry season from November to February and a hot and dry season from March to May. The vegetation cover consists of savannah grassland. In the traditional livestock management system, a variety of Zebu (Bos indicus) cattle breeds are raised, among these the Arab Zebu, with a welldeveloped dewlap and short horns, and the Mbororo (red Fulani) breed, a reddish brown cattle with long, whitish lyre-shaped horns (Flury et al., 2009). The Kouri cattle (Bos taurus) is an endemic breed in the Lake Chad area (Quéval et al., 1971). It is highly adapted to the shallow waters and crosses or swims from one island to another (Joshi and Phillips, 1957). Although cattle are kept in grazing systems, husbandry systems practiced by different ethnic groups of mobile pastoralists show specific differences. For example, the Gorane pastoralists breed Arab cattle and can avoid watering animals on surface water due to their excellent well building skills. The Arabs breed Arab cattle and are semi-nomadic. They leave their villages where they use water from wells; when pasture for their livestock gets scarce towards the end of the dry season, they migrate closer to the Lake Chads' shores. In contrast, the Fulani with their Mbororo cattle and the Buduma with their Kouri cattle live almost exclusively nomadic lifestyle (Loutan and Lamotte, 1984; MERA, 2008). They fully depend on surface water and use pastures on the shores of, and on islands within, Lake Chad.

\subsection{Study design, animals and treatment}

This study was designed as a single-arm intervention trial to determine the prevalence of Fasciola spp. at baseline and 6 months after treatment with triclabendazole in a typical Sahelian mobile pastoralist setting. The timing of the treatment was scheduled in a way that the cattle are treated prior to moving away from the Lake Chad wetlands towards drier areas 
with a presumably lower infection risk for a period of 5-6 months. In order to simulate mixed husbandry practices and to include all cattle breeds, animals from herds raised by all four groups of pastoralists were included in the study. Participating groups of pastoralists were partly selected randomly and partly through convenience sampling. Within the herds of each group, 25 cattle aged 1 year and above were randomly selected, individually marked with an ear tag and age, sex and body condition were recorded. A faecal sample was collected directly from the rectum of each animal. All selected animals received a single oral dose of triclabendazole $(12 \mathrm{mg} / \mathrm{kg})$. For the following 6 months, marked animals were kept together with non-tagged cattle and the pastoralists continued with their normal husbandry practices, except for that they were asked to not sell or slaughter tagged animals and to not administer anthelminthic treatment to marked animals during this period.

\subsection{Sample collection and parasitological analyses}

The baseline survey was carried out in April and May 2014. The follow-up survey took place from October to December 2014. At baseline and the 6-month treatment follow-up, faecal samples were collected from each animal. Approximately $3 \mathrm{~g}$ of faeces was fixed in a vial containing $30 \mathrm{ml}$ of sodium acetate-acetic acid-formalin (SAF) and marked with unique identifiers (IDs) of each animal. Samples were transferred to the parasitology laboratory at the Institute of Parasitology, Vetsuisse Faculty, University of Zurich (Zurich, Switzerland). For detection of $F$. gigantica eggs in SAF-fixed faecal samples, a sedimentation technique was employed. Eggs were enumerated under a microscope by experienced laboratory technicians.

\subsection{Statistical analysis}

Data were entered into Microsoft Access 2010 (Microsoft Corp.; Redmond, WA, USA) and internal consistency checks were done. Descriptive statistics and statistical modelling was performed using STATA version 13 (StataCorp, College Station, TX, USA) and R version 3.2.3. Generalized estimating equation (GEE) models for correlated binary outcomes 
and an independent correlation structure were applied to account for correlation within herds, with the individual pastoralist groups defined as cluster. Of note, GEE models have been reported to provide too narrow confidence intervals (Cis) if the numbers of clusters is low. However, random effect models, the widely used alternative, rely on distributional assumptions which are impossible to prove and which are likely to be violated if some clusters have 0 positive cases. The parasitological status of the tested cattle was described in terms of prevalence and faecal egg counts (FECs). A correction factor of 1.95 was estimated to translate FEC to eggs per gram (EPG) of faeces (linear regression, $N=18, R^{2}=$ 0.99, mean residual = 3.6 EPG). Age categories were defined as heifers and young bulls (1-3 years old) and cows and bulls (4 years and above).

\section{Results}

\subsection{Study flow}

During the baseline survey conducted in April and May 2014, in 14 mobile pastoralist groups, 375 cattle were enrolled and sampled. At follow-up in October and December 2014, 12 groups with a total of 198 animals were successfully traced, owing to a follow-up rate of 53\%. Two pastoralist groups (both Buduma) were lost to follow-up because they had entered deep into Lake Chad onto islands which were not accessible for the study team. The main reason for loss to follow-up ( $n=124$ animals) was related to separation of herds. Additionally, one animal had died and one animal was sold by the owner during the study (Fig. 1). 


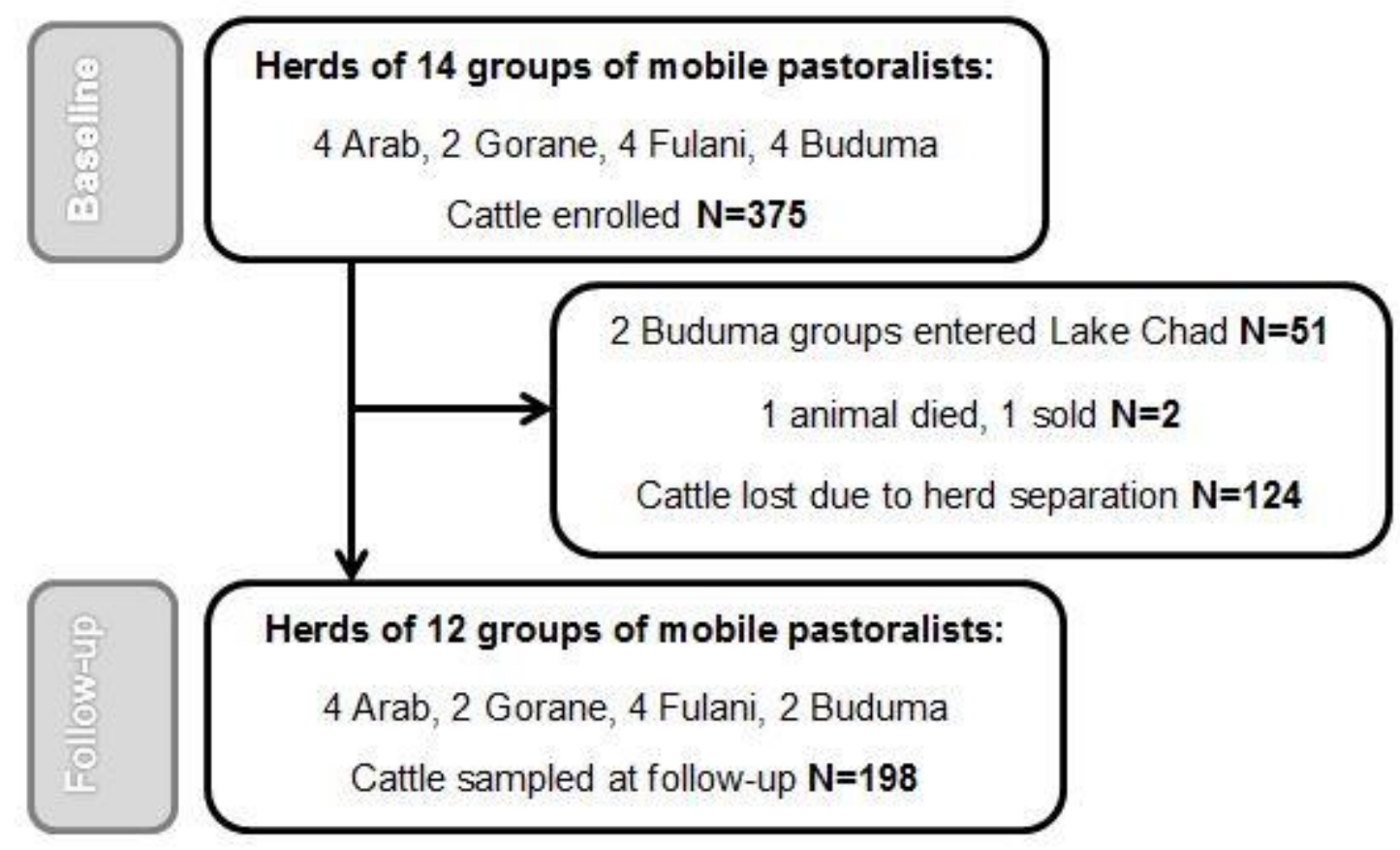

Fig. 1. Trial flow diagram of a single-arm intervention conducted on the eastern shores of Lake Chad in Chad from April to December 2014.

\subsection{Baseline characteristics}

The apparent baseline prevalence of $F$. gigantica infection among the 198 cattle with follow-up data was $41.9 \%(83 / 198,95 \% \mathrm{Cl} 35.2-48.9 \%)$ with no relevant difference compared to the 177 animals lost to follow-up (36.7\%, 95\% Cl 30.0-44.0\%). Within the 12 groups of mobile pastoralists with follow-up data, the number of sampled cattle varied from 2 to 28 animals. In two herds of the 12 mobile pastoralist groups, no F. gigantica infection was observed. Prevalence among animals from herds in positive groups ranged from $3 \%$ to $88 \%$. The 12 groups were composed of Arab $(n=4)$, Buduma $(n=2)$, Fulani $(n=4)$ and Gorane $(n=2)$ pastoralist. Both Gorane pastoralists and three out of the four Arab pastoralist groups kept exclusively cattle of the Arab Zebu breed. All Fulani and one Arab pastoralist group kept Mbororo cattle and both Buduma groups kept the Kouri breed cattle.

At baseline, cattle from the four Fulani herds were most affected by F. gigantica (mean prevalence was $68 \%$ ). Least affected were cattle from the herds of the Gorane pastoralists, where only one animal was found to shed F. gigantica eggs (3\%). The Mbororo and Kouri 
breed showed higher prevalence when compared to the Arab breed $(63 \%, 52 \%$ and $17 \%$, respectively). Among the 198 cattle, $90 \%$ were female. The age of animals ranged from 1 to 14 years. There was no significant difference in F. gigantica prevalence among male and female cattle (38\% vs. $42 \%)$ and between age groups (35\% in heifers/young bulls vs. $44 \%$ in cows and bulls). Baseline characteristics of the cattle of the retained animals are shown in Table 1.

\section{$<$ Table 1 near here}

\subsection{Prevalence at 6-month post-treatment follow-up}

Six months after treatment, $46 \%(95 \% \mathrm{Cl}: 39-53 \%)$ of the cattle were shedding F. gigantica eggs in faeces. In three mobile pastoralist groups, all animals were negative. Prevalence among animals from herds in positive groups ranged from $29 \%$ to $75 \%$, with half of the herds (6/12) showing prevalence above $60 \%$. While at baseline, cattle from the Fulani pastoralists where most affected, highest prevalence was seen in cattle herded by Arab pastoralists at the 6-month post-treatment follow-up (Fig. 2). 


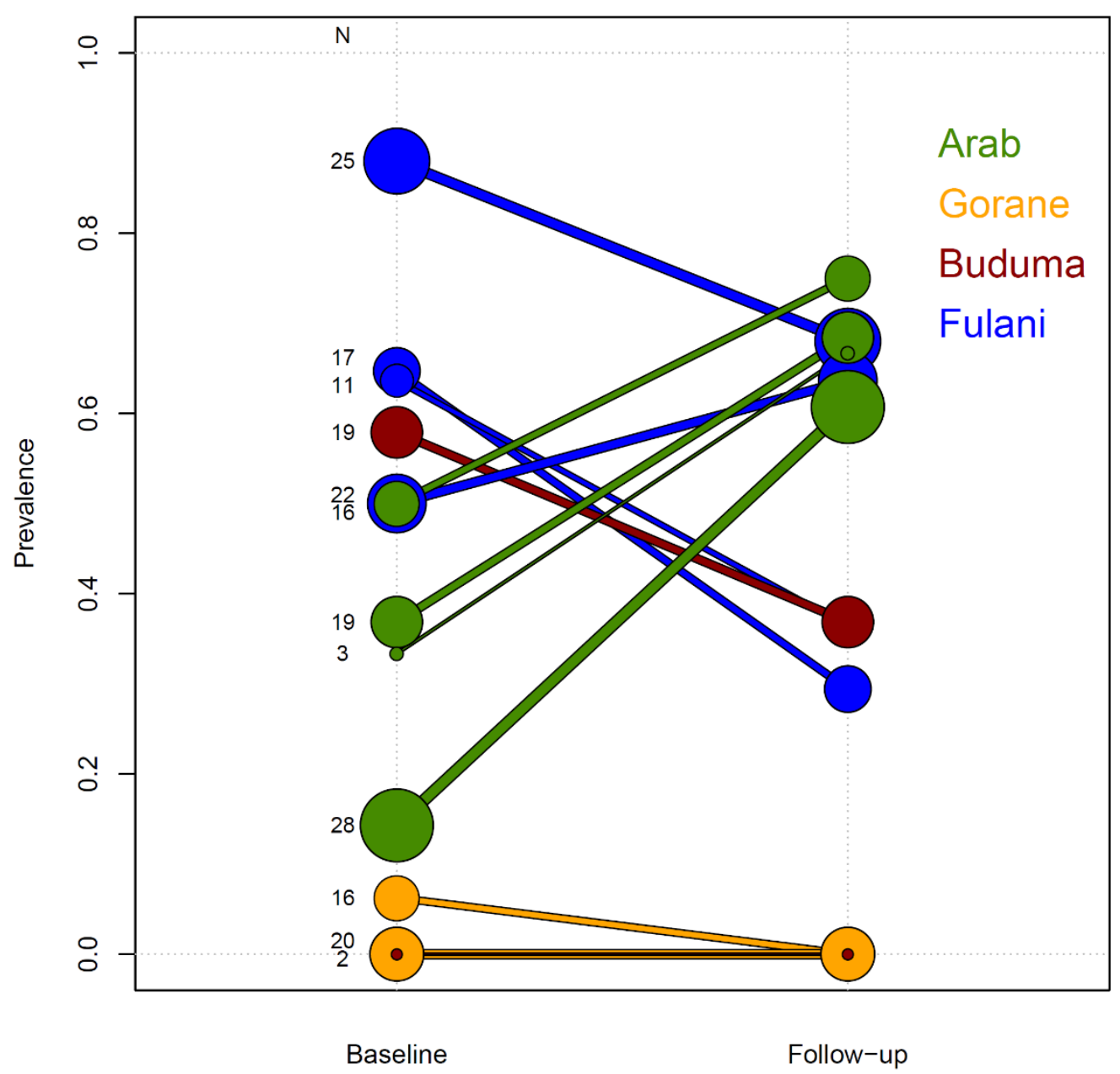

Fig. 2. Prevalence of bovine fascioliasis in 198 cattle from Arab, Gorane, Buduma and Fulani pastoralist husbandry system at baseline and 6-month post-treatment follow-up in a study conducted in 2014 at Lake Chad. The sizes of the individual circles reflect the number of animals sampled within the herds of individual mobile pastoralist groups at the two time points (baseline and 6-month follow-up).

Egg shedding was slightly lower at baseline (median 4 EPG, interquartile range (IQR) 26 EPG) compared to the 6-month post-treatment follow-up (median 8 EPG, IQR: 4-16 EPG) (Fig. 3). No noteworthy difference in EPG in heifers/young bulls compared to adult animals at baseline as well as at follow-up was detected. At follow-up, egg shedding was slightly higher in both age groups compared to baseline. 


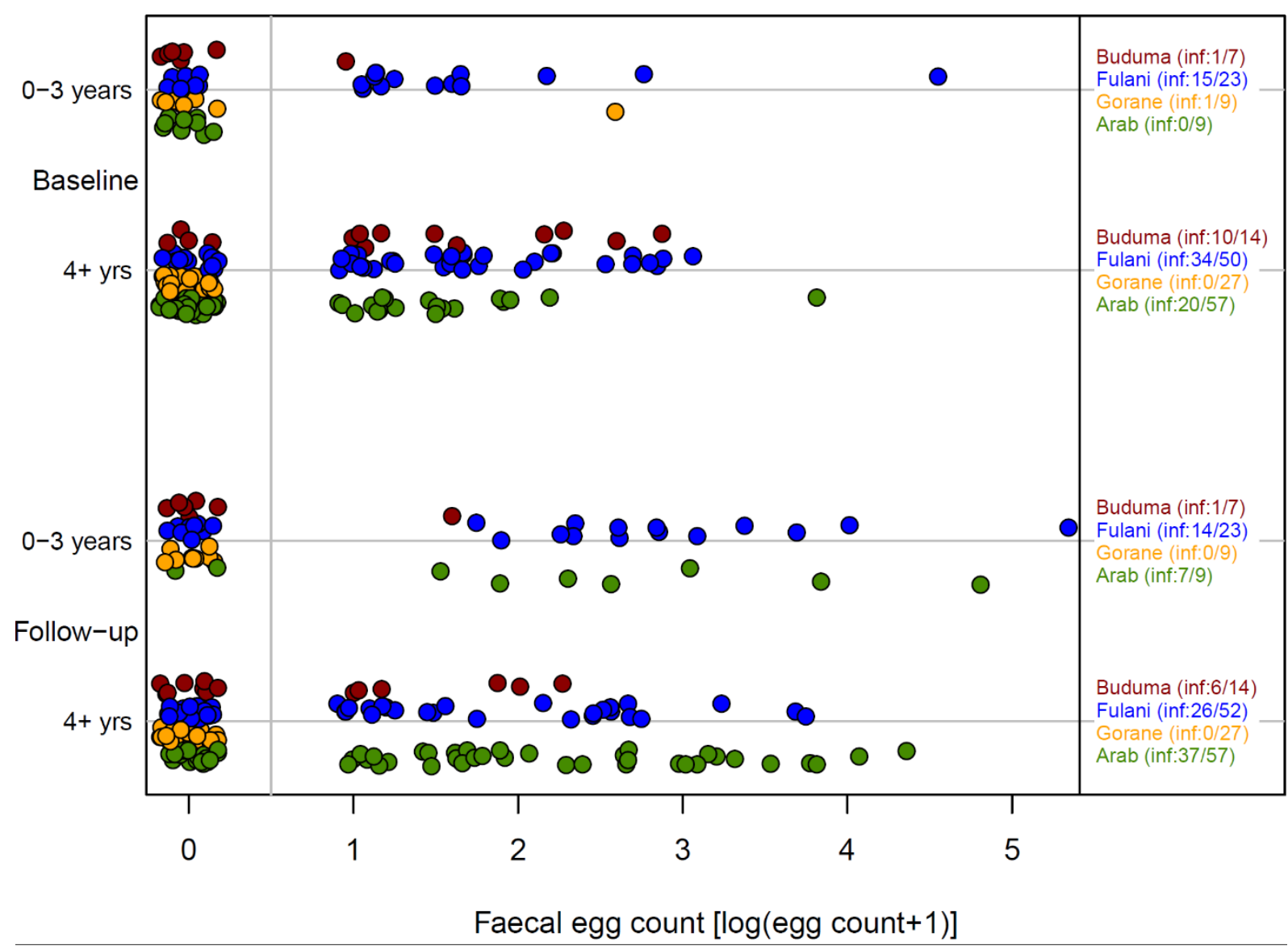

Fig. 3. Faecal egg count in 198 cattle from four different husbandry systems in the Lake Chad area in 2014, stratified by two age categories before and 6-month after treatment with triclabendazole (points jittered to avoid overplotting).

\subsection{Risk factors for re-infection}

At follow-up, the prevalence in cattle infected at baseline was significantly higher compared to cattle not infected at baseline $(56 \%$ vs. $38 \%$, odds ratio (OR) $2.1,95 \% \mathrm{Cl} 1.2-$ 3.7, $\mathrm{p}=0.01)$. Prevalence was balanced in heifers/young bulls and adult animals $(46 \% \mathrm{vs}$. $46 \%$, OR 1.0, $95 \% \mathrm{Cl} 0.5-1.9$ ) (Table 2). There was no evidence that age of cattle is a determinant explaining the prevalence of infection. Body condition at baseline and follow-up did not differ between surveys; at baseline and the 6-month post-treatment follow-up, approximately $26 \%$ of the animals were in good body condition and $73 \%$ were in poor body condition. 
Among the different cattle breeds, the Mbororo cattle were at a significantly higher odds of a F. gigantica infection 6 months post-treatment, compared to Arab and Kouri cattle (Mbororo: OR 2.8, 95\% Cl 1.5-5.0; Kouri: OR 1.1, 95\% Cl 0.3-2.6). The husbandry system of the Arab pastoralists seems to encompass the highest risk, since $67 \%$ of the cattle kept in Arab husbandry system were re-infected, followed by the Fulani husbandry system with $53 \%$ and the Buduma and Kouri with $33 \%$ each. In the husbandry system of the Gorane pastoralists, no fascioliasis case was detected at follow-up, compared to one case at baseline.

\section{$<$ Table 2 near here $>$}

\section{Discussion}

This study assessed baseline and 6-month post-treatment prevalence of F.gigantica infection in cattle after a single oral dose of triclabendazole $(12 \mathrm{mg} / \mathrm{kg})$ in mobile pastoralist husbandry systems at Lake Chad. To our knowledge, we present the first data on triclabendazole treatment in naturally infected cattle from central Africa. Our study found a baseline prevalence of $F$. gigantica infection among cattle from 14 herds of $41.9 \%$. As in the present study, longitudinal studies in pastoralist communities are associated with substantial loss to follow-up. However, the observed baseline prevalence did not differ much between animals followed and those lost $(41.9 \%$ vs. $36.7 \%)$. Variance of infection at the unit of the herd, varied in the different husbandry systems; the baseline prevalence ranged between $0 \%$ and $88 \%$, thus supporting the findings from a preceding abattoir study (Jean-Richard et al., 2014). Variation in infection may be explained by the social-ecological contexts of different ethnic groups of mobile pastoralism that translates to the individual husbandry systems. Cattle herded by Gorane pastoralists have a minimal risk of $F$. gigantica infection, in contrast to cattle herded by Arab, Fulani and Buduma pastoralists, as the latter drive their herds deep into the shores and the shallow waters of Lake Chad. Six months after single-dose triclabendazole treatment, a prevalence of $46 \%$ was observed. In fenced livestock, it has been shown that post-treatment re-infection patterns are largely dependent on pasture 
infestation, and hence, the presence and abundance of intermediate host snails (Brunsdon, 1980). Our study was carried out in cattle herded in a highly mobile way and infection prevalence at 6 months post-treatment was similar to the baseline situation. Importantly, the study was conducted under 'real-life' conditions. Consequently, the exact pattern of parasite clearance after administration of triclabendazole and reinfection post-treatment remain largely unknown, as we did not assess efficacy of triclabendazole (e.g. 3 weeks posttreatment to determine whether or not infection prevalence and intensity really dropped). Hence, we cannot rule out that some animals have not been cured. Several studies have shown an efficacy of $90-100 \%$ in naturally infected cattle, and based on these findings our assumption is that a single oral dose of triclabendazole is highly efficacious (Craig and Huey, 1984; Lecuyer et al., 1985; Stansfield et al., 1987). Within a few days after treatment, cattle show no or only light $F$. gigantica infection, while rates observed 6 months post-treatment are due to reinfection. We were surprised that the prevalence of F. gigantica infection at followup was slightly higher than at baseline, and indeed, 6-month post-treatment egg shedding was above the baseline level. These observations might be explained, at least partially, due to suspected high pasture and water point contamination, resulting from high livestock numbers on the shores of Lake Chad towards the end of the dry season, prior to moving out of the Lake Chad wetlands (Jean-Richard et al., 2015). Our results are not conclusive whether re-infection occurred still in the Lake Chad area or during migration outside the wetlands. We suggest that in a future study, treatment should be administered shortly after cattle leave the wetland areas, which would involve mobile communication with livestock holders. Treatment at the end of the rainy season, when cattle return to the wetlands of Lake Chad would likely lead to a rapid re-infection again. A more detailed understanding of the transmission dynamics of $F$. gigantica in relation to the seasonal migration between wetlands and dryland pasture is warranted to develop an effective strategic control programme using triclabendazole for the management of bovine fascioliasis in the Lake Chad area.

Baseline prevalence might be an underestimate of the real situation because about $40 \%$ $(158 / 375)$ of the ear-tagged cattle were treated with albendazole in late 2013. Yet, given the 
limited efficacy of a single dose of albendazole against Fasciola and the observed rapid reinfection, this effect seems negligible (Keyyu et al., 2009). In addition, studies report the specificity of the sedimentation method being $100 \%$, though its sensitivity level lies between 63\% and 82.5\% (Anderson et al., 1999; Duthaler et al., 2010). Also, fascioliasis has a prepatency phase of 8-13 weeks, where no eggs are shed in faeces (Mehlhorn, 2008). These factors may further point out that the prevalence reported here represents an underestimate and the 'true' prevalence might be considerably higher.

In conclusion, this study shows that a single treatment with triclabendazole for bovine fascioliasis is not effective in the specific setting of exposure to highly contaminated wetlands. To establish an adapted, effective treatment plan for the control of bovine fascioliasis at Lake Chad, a more strategic approach is needed, combining the use of highly effective drugs with specific spatio-temporal knowledge on intermediate host snail abundance and of the movement out of the high risk areas analogous to a comparable study on the effectiveness of a single-dose ivermectin treatment on gastro-intestinal nematodes in the dry season (Zinsstag et al., 1994).

\section{Conflict of interest}

The authors have no conflict of interest.

\section{Acknowledgements}

We thank the participating pastoralist groups and the district veterinary health authorities for their high level of cooperation and for their on-going support. Ms. Elisabeth Escher is thanked for her skilled assistance during the parasitological analyses at the Institute for Parasitology, University of Zurich. This study would not have been possible without the excellent work of the field team: Ali A. Abakar, Moussa Issa, Ferdinand Mbainaissem and Annour A. Batil. The authors thank Novartis Animal Health (Basel, Switzerland) for the donation of the triclabendazole product. 
Funding: This study was funded by the Swiss National Science Foundation (SNSF; Bern, Switzerland, grant-no.: 320030141246), the Rudolf Geigy Foundation (Basel, Switzerland) and the "Freie Akademische Gesellschaft" (Basel, Switzerland).

\section{References}

Akkari, H., Gharbi, M., Darghouth, M.A., 2011. Infestation of tracer lambs by Fasciola hepatica in Tunisia: determining periods for strategic anthelmintic treatments. Rev. Sci. Tech. Off. Int. Epiz. 30, 917-929.

Anderson, N., Luong, T.T., Vo, N.G., Bui, K.L., Smooker, P.M., Spithill, T.W., 1999. The sensitivity and specificity of two methods for detecting Fasciola infections in cattle. Vet Parasitol 83, 15-24.

Bouchet, A., Graber, M., Finelle, P., Desrotour, J., Macon, G., 1969. Le parasitisme du zébu dans l'ouest de la République Centrafricaine. Rev Elev Med Vet Pays Trop 22, 373383.

Brunsdon, R.V., 1980. Principles of helminth control. Vet Parasitol 6, 185-215.

Craig, T.M., Huey, R.L., 1984. Efficacy of triclabendazole against Fasciola hepatica and Fascioloides magna in naturally infected calves. Am J Vet Res 45, 1644-1645.

De Haan, C., Dubern, E., Garancher, B., Quintero, C., 2014. Pastoralism development in the Sahel: a road to stability? Global Center on Conflict, Security and Development, The World Bank.

Duthaler, U., Rinaldi, L., Maurelli, M.P., Vargas, M., Utzinger, J., Cringoli, G., Keiser, J., 2010. Fasciola hepatica: comparison of the sedimentation and FLOTAC techniques for the detection and quantification of faecal egg counts in rats. Exp Parasitol 126, 161-166.

Flury, C., Ngandolo, B.N.R., Müller, B., Zinsstag, J., Kadarmideen, H.N., 2009. Molecular characterization of two common Chadian cattle breeds. AGRI 44, 67-76.

Greter, H., Cowan, N., Ngandolo, B.N., Kessely, H., Alfaroukh, I.O., Utzinger, J., Keiser, J., Zinsstag, J., 2016. Treatment of human and livestock helminth infections in a mobile 
pastoralist setting at Lake Chad: Attitudes to health and analysis of active pharmaceutical ingredients of locally available anthelminthic drugs. Acta Trop (in press; doi: 10.1016/j.actatropica.2016.05.012).

Jean-Richard, V., Crump, L., Abicho, A.A., Abakar, A.A., Mahamat, A., 2nd, Bechir, M., Eckert, S., Engesser, M., Schelling, E., Zinsstag, J., 2015. Estimating population and livestock density of mobile pastoralists and sedentary settlements in the southeastern Lake Chad area. Geospat Health 10, 307.

Jean-Richard, V., Crump, L., Abicho, A.A., Nare, N.B., Greter, H., Hattendorf, J., Schelling, E., Zinsstag, J., 2014. Prevalence of Fasciola gigantica infection in slaughtered animals in south-eastern Lake Chad area in relation to husbandry practices and seasonal water levels. BMC Vet Res 10, 81.

Joshi, N.R., Phillips, R.W., 1957. Les bovins d'Afrique: types et races. Organisation des Nations Unies pour l'Alimentation et l'Agriculture, Rome.

Kaplan, R.M., 2001. Fasciola hepatica: a review of the economic impact in cattle and considerations for control. Vet Ther 2, 40-50.

Keiser, J., Engels, D., Büscher, G., Utzinger, J., 2005. Triclabendazole for the treatment of fascioliasis and paragonimiasis. Expert Opin Investig Drugs 14, 1513-1526.

Keyyu, J.D., Kyvsgaard, N.C., Monrad, J., Kassuku, A.A., 2009. Effectiveness of strategic anthelmintic treatments in the control of gastrointestinal nematodes and Fasciola gigantica in cattle in Iringa region, Tanzania. Trop Anim Health Prod 41, 25-33.

Lecuyer, B., Bordas, C., Marchand, C., Nguyen, H., Sourd, C., 1985. Investigation of the fasciolicide activity of triclabendazole in cattle in Nièvre, France. Bull Soc Vet Prat France 69, 507-513.

Loutan, L., Lamotte, J.M., 1984. Seasonal variations in nutrition among a group of nomadic pastoralists in Niger. Lancet 323, 945-947.

Mehlhorn, H., 2008. Encyclopedia of parasitology, 3rd Edition. Springer, Berlin and Heidelberg. 
MERA 2008. Plan National de Devéloppement de l'Elevage 2009-2016. (N'Djaména, Ministère de l'Elevage et des Ressources Animales du Tchad).

Quéval, R., Petit, J.P., Tacher, G., Provost, A., Pagot, J., 1971. Le Kouri: race bovine du lac Tchad. I. Introduction générale à son étude zootechnique et biochimique: origines et écologie de la race. Rev Elev Med Vet Pays Trop 24, 667-687.

Rapic, D., Dzakula, N., Sakar, D., Richards, R.J., 1988. Comparative efficacy of triclabendazole, nitroxynil and rafoxanide against immature and mature Fasciola hepatica in naturally infected cattle. Vet Rec 122, 59-62.

Richards, R.J., Bowen, F.L., Essenwein, F., Steiger, R.F., Buscher, G., 1990. The efficacy of triclabendazole and other anthelmintics against Fasciola hepatica in controlled studies in cattle. Vet Rec 126, 213-216.

Stansfield, D.G., Lonsdale, B., Lowndes, P.A., Reeves, E.W., Schofield, D.M., 1987. Field trials of triclabendazole against mixed age infections of Fasciola hepatica in sheep and cattle. Vet Rec 120, 459-460.

Suleiman, A., Jackson, E.L., Rushton, J., 2015. Challenges of pastoral cattle production in a sub-humid zone of Nigeria. Tropical animal health and production 47, 1177-1185.

Tager-Kagan, P., 1978. Contribution à l'étude de la fasciolose au Niger. Rev Elev Med vet Pays trop 31, 437-442.

Wamae, L.W., Hammond, J.A., Harrison, L.J., Onyango-Abuje, J.A., 1998. Comparison of production losses caused by chronic Fasciola gigantica infection in yearling Friesian and Boran cattle. Trop Anim Health Prod 30, 23-30.

WHO 2007. Report of the WHO informal meeting on use of triclabendazole in fascioliasis control. (Geneva, World Health Organziation).

WHO 2015. Investing to overcome the global impact of neglected tropical diseases. Third WHO report on neglected tropical diseases. (Geneva, World Health Organization).

Zinsstag, J., Ankers, P., Njie, M., Itty, P., Monsan, V., Kaufmann, J., Smith, T., Pandey, V.S., Pfister, K., 2000. Effect of strategic gastrointestinal nematode control on faecal egg count in traditional West African cattle. Vet Res 31, 259-266. 
Zinsstag, J., Njie, M., Kaufmann, J., Pfister, K., 1994. Prolonged suppression of trichostrongyle egg output of N'Dama cattle by a single larvicidal treatment. Acta Trop $58,99-103$. 


\section{Table 1}

Baseline characteristics and Fasciola gigantica prevalence of 198 cattle from mobile pastoralist husbandry systems at Lake Chad in April and May 2014.

\begin{tabular}{|c|c|c|}
\hline Characteristics of cattle & $\mathbf{N}(\%)$ & Prevalence (\%) \\
\hline \multicolumn{3}{|l|}{ Sex } \\
\hline Female & $177(90 \%)$ & $42 \%$ \\
\hline Male & $21(10 \%)$ & $38 \%$ \\
\hline \multicolumn{3}{|l|}{ Age categories } \\
\hline Heifers and young bulls & $48(25 \%)$ & $35 \%$ \\
\hline Cows and bulls & $150(75 \%)$ & $44 \%$ \\
\hline \multicolumn{3}{|l|}{ Breed } \\
\hline Arab & $84(42 \%)$ & $17 \%$ \\
\hline Kouri & $21(11 \%)$ & $52 \%$ \\
\hline Mbororo & $93(47 \%)$ & $63 \%$ \\
\hline \multicolumn{3}{|l|}{ Husbandry system } \\
\hline Arab & $66(33 \%)$ & $30 \%$ \\
\hline Gorane & $36(18 \%)$ & $3 \%$ \\
\hline Fulani & $75(38 \%)$ & $68 \%$ \\
\hline Buduma/Kouri & $21(11 \%)$ & $52 \%$ \\
\hline
\end{tabular}


Table 2

Prevalence of Fasciola gigantica in cattle from mobile pastoralist husbandry systems at Lake Chad in October and December 2014, 6 months after triclabendazole treatment, stratified by risk factors.

\begin{tabular}{lcccc}
\hline Characteristics of cattle & Positive [\% (N)] & Negative [\% (N)] & OR & 95\% Cl \\
\hline Age category & & & Ref \\
Heifers and young bulls & $46 \%(22)$ & $54 \%(26)$ & 1.0 & $0.5-1.9$ \\
Cows and bulls & $46 \%(69)$ & $54 \%(81)$ & & \\
Sex & & & Ref & \\
Female & $46 \%(81)$ & $54 \%(96)$ & 1.0 & $0.4-2.7$ \\
Male & $48 \%(10)$ & $52 \%(11)$ & & \\
Breed & & $66 \%(55)$ & Ref & \\
Arab & $34 \%(29)$ & $41 \%(38)$ & 2.8 & $1.5-5.0$ \\
Mbororo & $59 \%(55)$ & $67 \%(14)$ & 1.1 & $0.3-2.6$ \\
Kouri & $33 \%(7)$ & &
\end{tabular}

Husbandry system ${ }^{a}$

Gorane

Arab

Fulani

Buduma/Kouri

Baseline infection status

F. gigantica-negative

F. gigantica-positive
0

$67 \%(44)$

$53 \%(40)$

$33 \%(7)$

$38 \%(44)$

$56 \%(47)$
100\% (36)

$33 \%(22)$

47\% (35)

67\% (14)

\footnotetext{
${ }^{a}$ Statistical analysis omitted because husbandry system is nested within herd (cluster).
} 